\title{
Virtual and Augmented Reality in Education
}

\author{
Daina GUDONIENE, Danguole RUTKAUSKIENE \\ Kaunas Technology University, Faculty of Informatics \\ Studentu St. 50, LT-51368, Kaunas, Lithuania \\ daina.gudoniene@ktu.lt, danguole.rutkauskiene@ktu.lt
}

\begin{abstract}
Over the past few years, VR and AR have been gaining popularity very fast. Implementations of new technologies caused the development of AR and VR. Both virtual reality and augmented reality is not yet widely used in higher education and the purpose of this paper is to provide a model for the development of integrated learning objects based on VR and AR approach where VR and AR objects could be integrated into other educational content as learning objects by creating integrated learning programs, learning scenarios or etc. This paper provides the literature review on virtual and augmented reality and analysis of integrated models for educational process implementation. The suggested model validates authors' conclusions and leads to recommendations for its implementation.
\end{abstract}

Keywords: virtual reality, augmented reality, integrated model, education.

\section{Introduction}

During the last years, virtual and augmented reality has been quickly gaining popularity. New technologies and wider use of the internet led to the development of VR/AR applications. Recently, a demand to apply three-dimensional (3D) information visualization for learning has prompted the development of learning objects (LO) practices.

Virtual reality (VR) and augmented reality (AR) are the ways, which can be used to create LOs and satisfy their typical requirements. Technological implementations in the learning process will enhance deeper perception through the multisensorial environment (Heverton, et al 2016). That are the environments, which allow integrating several human senses (sight, hearing, touch, smell and taste are experimental) (Gallace and Spence, 2014). LOs enable the visual transfer of knowledge which can be combined with teacher's explanations concerning the images displayed.

Virtual reality enables the user to engage with a computer-generated environment, which is supported by computer graphics systems while using diverse display and interface devices. This platform provides teachers with various teaching methods and tools, but the most important feature of VR is that it induces learners' skills in analyzing problems and investigate new notions and knowledge. Virtual reality is a shareable platform where learners can interact with objects, which are provided by a system. For users it provides interaction, which can be divided in three kinds: navigation (the main 
feature of virtual reality, performed in the 3D environment. Navigation enables the user to explore, search and maneuver in 3D environment), selection/ manipulation (provides interaction with virtual objects), system control tasks (possibility to control modes of the interaction or state of the system). An effective simulation is one that is able to place a user in a situation, which is close, if not completely identical to the scenario in which the system is attempting to simulate (Endsley, 2016).

Wide distribution of the educational content with three points identified by Yin (2017): Define, Design and Development, and Dissemination to share the best teaching practices.

\section{Literature review on the VR and $A R$ implementation into practice}

Much research were done on virtual and augmented reality. For a long time, researchers argue if virtual and augmented reality can and should change an educational process. There are different opinions about both of them. Nevertheless, the more inquiries are done, the more positive facts appear.

To start with virtual reality, one of the latest research showed that students, who were studying engineering with the help of virtual reality were highly motivated by the given tasks and worked even during their free time (Floyd et al, 2017). The emergence of virtual reality technology offers a training supplement for surgeons -a faster, safer, and less costly way to enable students to practice surgical procedures. The software, which can be surprisingly realistic, allows the student to practice a wide range of surgical procedures, repeating each one with somewhat different conditions, until the student is comfortable with the process and ready for the traditional modes of surgical practice. This reduce risks to patients and the need for the expensive use of animals in training. Faculty could make at least some of the improvements in learning outlined here without using digital technology, but this would require an extraordinary commitment of time and effort on the part of faculty members and students. With limited effort, the new digital technology simply makes learning much more interesting-even exciting (Newman and Scurry, 2015).

The use of virtual reality in experimental psychology ground has increased a lot over the last twenty-five years and a lot of researches were done to find out the effect, advantages, and disadvantages for learning with VR. Many advantages were found from different scientists: it allows greater control of the stimuli and more varied responses (Freeman et al, 2016; Lee et al, 2015) where the generation of varying levels and combinations of multimodal sensory input potentially allowing audio, haptic, olfactory, and motion to be experienced simultaneously to the graphically rendered environment or objects; (Wilson and Soranzo, 2015).

Innovations in VR and AR have the potential to significantly enhance neurosurgery, revolutionize resident education, and ultimately help save lives. VR will likely become integral in surgery and the development of tactical surgical approaches during preoperative and intraoperative assessments. Future applications of this technology are limitless and will allow for efficient and effective real-time navigation in the operating room (Pelargos et al, 2017).

The scientist also proved that augmented reality helps to remember everything better and longer than using three-dimensional virtual environment. Research has shown 
that content learned through augmented reality experiences is memorized more strongly than through non-augmented reality experiences (Diegmann, et al. 2015). Results showed that students who learned from the three-dimensional virtual environment learning results were better compared to the control group having learning process in the usual learning environment.

However VR objects for education deals with the technical aspects of mobile devices, their operational environment and constraints. The second category defines the learner context elements (e.g. aims and objectives of the learner, prerequisites, etc.) (Stuikys et al, 2017).

AR technology provides a better means of students learning in an interactive environment. It allows students interact while enabling social communication. AR technology introduces a new type of automated applications and to enhance the effectiveness and attractiveness of learning environment for the students in a real-world scenario (Weng et al, 2016).

As a powerful educational tool, AR could result in less time in training and less time to master a task. However, to achieve this it is necessary to identify the right scenarios and design appropriate learning experiences.

Usage of multimedia has been useful, not only in formal education, but also in nonformal education. The researchers say that when the learner has an ability not only to hear but also to see and be interacted with the learning environment, they can remember about $80 \%$ of whole experienced information (Jamalahdin et al, 2017). However smartphone-based augmented reality applications make users able to travel through their physical environment while looking at their augmented world through a mobile device (Radu, 2014) but the problem is that the mobile device limits the user's ability to physically interact with the augmented space.

\section{A methodology of implementation}

The review and analysis of related papers were used for searching for the advantages of the integrated platform for virtual and augmented reality implementation.

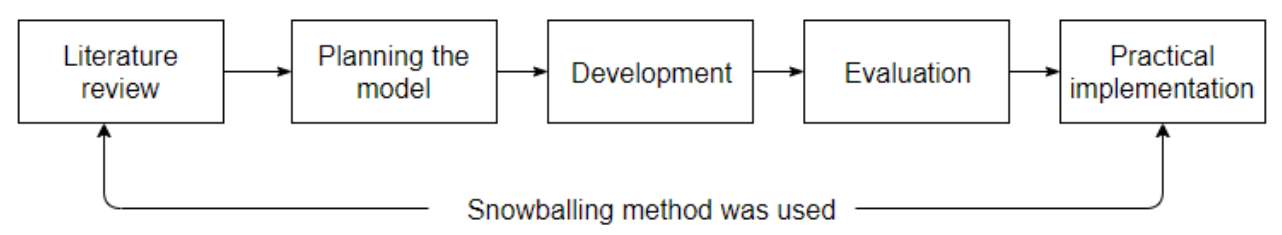

Fig. 1. Implementation model.

Literature review as a theoretical framework was designed to present the results of the related researches on the benefits of technologies for education and need of the new integrated platform for new technological solutions. Practical implementation phase was evaluated and presented in the case Experiment. Snowballing method was used in implementation. 


\section{Development of the educational environment for learning objects based VR and AR}

In the planning stage authors have intended several steps related to integrated LO design model based on virtual and augmented reality: integrated design, using VR and AR; introduce and relate to the ,real world"; demonstrate and discuss; explore and mine; construct and test; share and critique; extend and develop; share. (See figure 2). The learning object based on virtual reality could be used also in another educational content. This model can be used to guide the design, development, and evaluation of the learning environment.

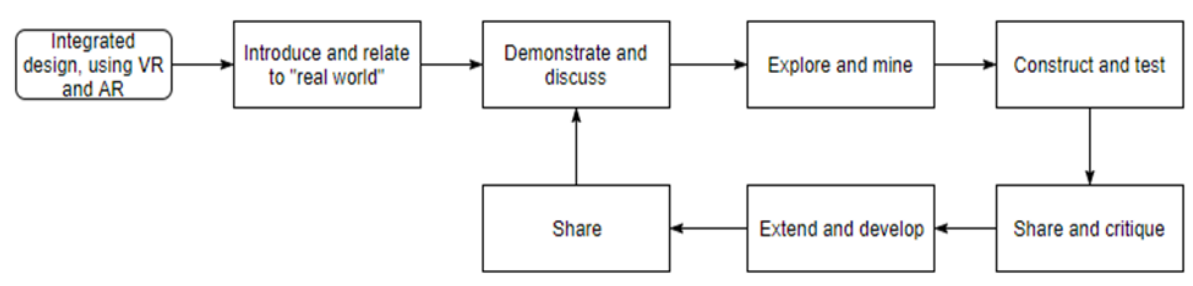

Fig. 2. The conception of development VR and AR model.

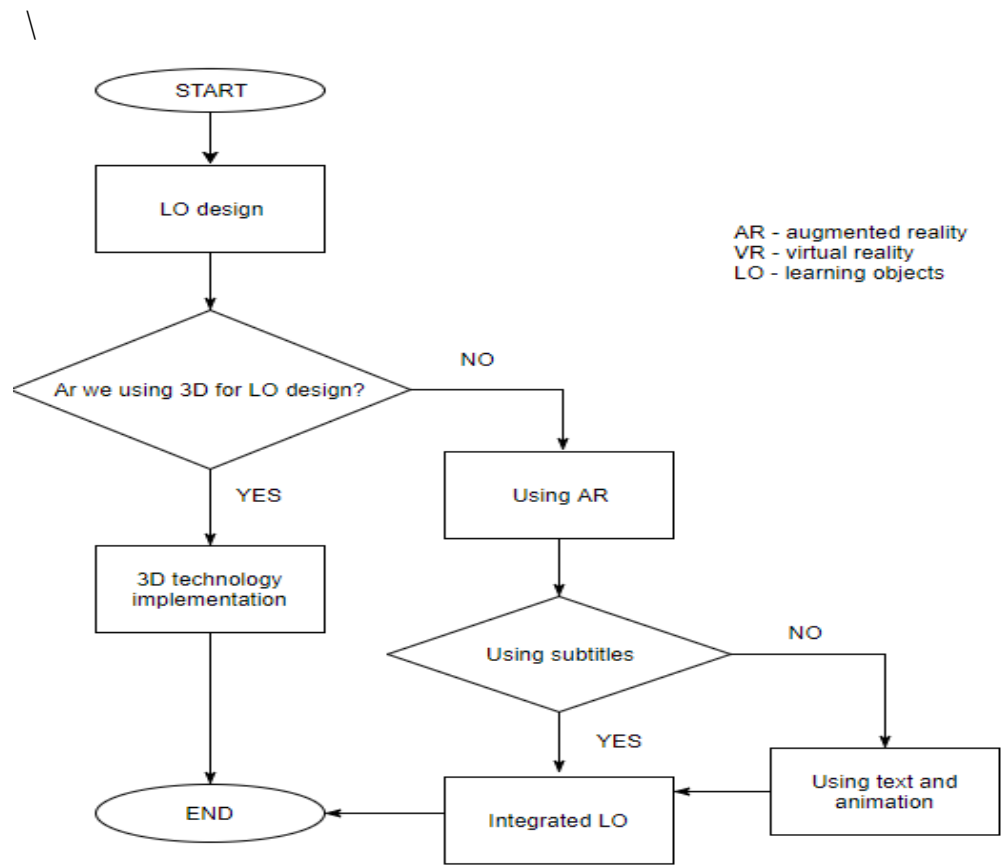

Fig. 3. Integrated LO design algorithm. 
In the development stage an algorithm was made which will be implemented using different VR technologies. For, the authors have selected two different ways of virtual reality: three-dimensional technologies and augmented reality.

Three-dimensional (3D) technologies have become a foundation for almost all modern computer games and virtual worlds. A lot of educators and educational institutions foresee great potential in the use of three-dimensional virtual environments stimulations and games for learning and teaching different subjects.

Augmented reality experiences can take a variety of forms. This type of augmented reality is mostly like the three-dimensional reality. The user cannot immerse in the augmented reality experiences. Webcam-based augmented reality needs a computer camera to record a physical real-world space and disclose an augmentation on a screen, such as a projector or a computer desktop, allowing the users to use their hands to manipulate the augmented reality content easily.

The recent CLSAR survey results have shown that the students have shown positive conceptions, with stronger perceptions of learning science by AR as increasing motivation and interaction (Cheng, 2018).

The authors need to assure usage of educational environment for the learning process as open environment assuring the self-directed learning approach. There is a need for three different levels of communication and technological environment to design LO based on augmented and virtual reality.

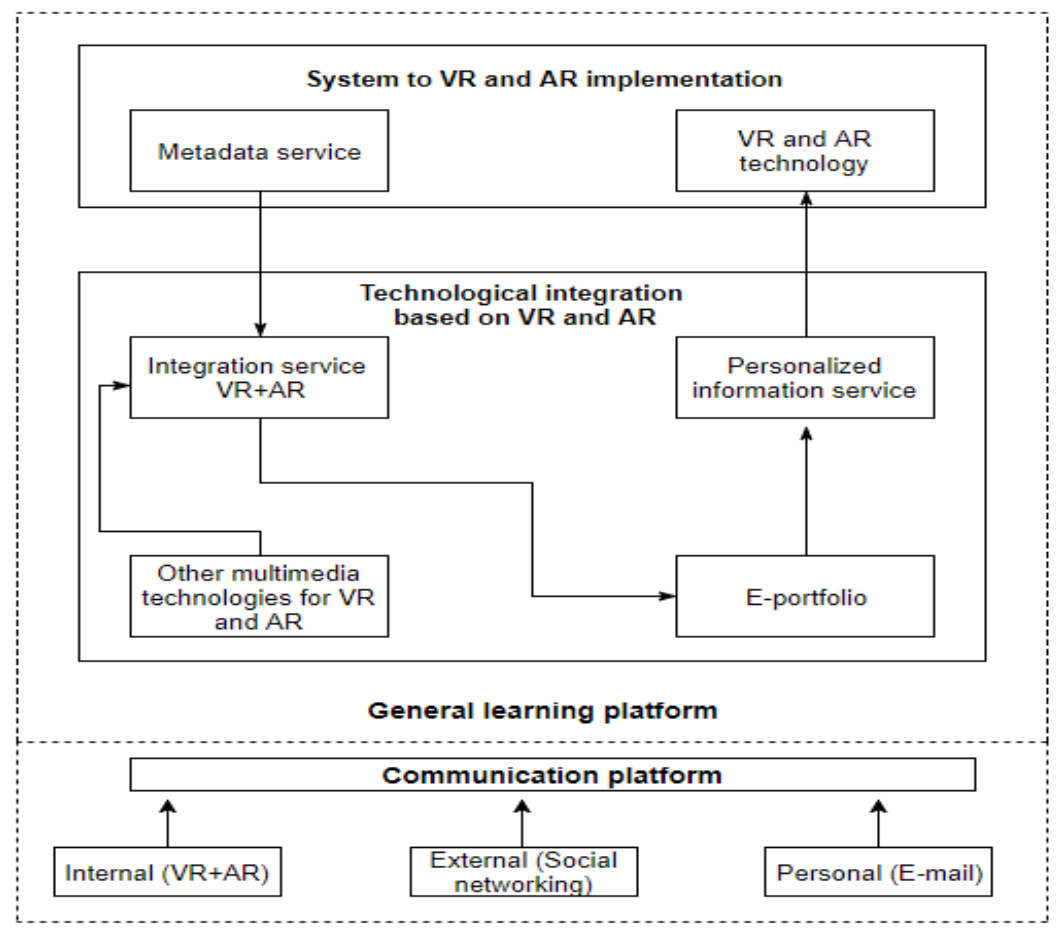

Fig. 4. Educational environment for learning objects based on VR and AR implementation. 
The functionality of educational environment will assure the insertion of educational content (including different format learning objects), testing, and content development: development of digital material and metadata description; learning objects design, courses design and open access management; development of tests and assignments and relation with the necessary program; virtual learning environment and user's administration.

The educational environment based on Drupal content management system will assure self directed learning approach, by using open resources (VR and AR) designed and integrated into educational environment.

\section{The case experiment}

The comparative analysis is developed to compare the functionality of the suggested model functionality and the virtual learning environment (see Table 1).

Table 1. The comparison of the features VLE and IS with Implemented model.

\begin{tabular}{|c|c|c|c|}
\hline Features & Description of the feature & $\begin{array}{l}\text { Integrated IS } \\
\text { using the model } \\
\text { (Drupal) }\end{array}$ & $\begin{array}{l}\text { Virtual } \\
\text { Learning } \\
\text { Environment }\end{array}$ \\
\hline $\begin{array}{l}\text { Discussion } \\
\text { forum }\end{array}$ & $\begin{array}{l}\text { Instructors can use some } \\
\text { personal settings and settings } \\
\text { for students. Allow them to } \\
\text { create groups. }\end{array}$ & $\begin{array}{l}\text { Could be } \\
\text { integrated. }\end{array}$ & Implemented \\
\hline $\begin{array}{l}\text { File } \\
\text { sharing }\end{array}$ & $\begin{array}{l}\text { Students have personal folders } \\
\text { to which they can add or } \\
\text { remove files. }\end{array}$ & $\begin{array}{l}\text { Using Internal } \\
\text { collaboration } \\
\text { tools. }\end{array}$ & Implemented \\
\hline $\begin{array}{l}\text { Internal } \\
\text { mail }\end{array}$ & $\begin{array}{l}\text { Students must have online } \\
\text { email addresses }\end{array}$ & $\begin{array}{l}\text { Based on } \\
\text { discussion } \\
\text { forums (internal } \\
\text { communication) }\end{array}$ & Implemented \\
\hline $\begin{array}{l}\text { Chat in } \\
\text { real time }\end{array}$ & $\begin{array}{l}\text { The system creates chat } \\
\text { rooms. The virtual class tool } \\
\text { supports a structured way to } \\
\text { ask questions and instructors } \\
\text { can provide answers }\end{array}$ & Not assured & Implemented \\
\hline $\begin{array}{l}\text { Video- } \\
\text { System }\end{array}$ & $\begin{array}{l}\text { The system supports the } \\
\text { ability to transfer video }\end{array}$ & $\begin{array}{l}\text { Could be } \\
\text { supported video } \\
\text { learning objects }\end{array}$ & Implemented \\
\hline $\begin{array}{l}\text { White } \\
\text { board }\end{array}$ & $\begin{array}{l}\text { The system is expressed as } \\
\text { white board which may have a } \\
\text { lot examples for the course. }\end{array}$ & Not assured & Implemented \\
\hline Calendar & $\begin{array}{l}\text { Instructors can record course- } \\
\text { linked events in course } \\
\text { calendars. }\end{array}$ & $\begin{array}{l}\text { Could be } \\
\text { integrated }\end{array}$ & Implemented \\
\hline $\begin{array}{l}\text { Progress } \\
\text { tracking }\end{array}$ & $\begin{array}{l}\text { Students may marks for their } \\
\text { tasks and can compare it. }\end{array}$ & To be followed & Implemented \\
\hline
\end{tabular}




\begin{tabular}{|l|l|l|l|}
\hline Sync & Assured and implemented & $\begin{array}{l}\text { Assured and } \\
\text { could be } \\
\text { integrated }\end{array}$ & Implemented \\
\hline $\begin{array}{l}\text { Virtual } \\
\text { Reality }\end{array}$ & Supporting virtual reality 3D & $\begin{array}{l}\text { Assured and } \\
\text { could be } \\
\text { integrated }\end{array}$ & $\begin{array}{l}\text { Could be } \\
\text { integrated VR or } \\
\text { AR based } \\
\text { learning objects }\end{array}$ \\
\hline $\begin{array}{l}\text { Augmente } \\
\text { d Reality }\end{array}$ & Supporting Augmented reality & $\begin{array}{l}\text { Assured and } \\
\text { could be } \\
\text { integrated }\end{array}$ & $\begin{array}{l}\text { Could be } \\
\text { integrated VR or } \\
\text { AR based } \\
\text { learning objects }\end{array}$ \\
\hline $\begin{array}{l}\text { Connection } \\
\text { with social } \\
\text { networks }\end{array}$ & implemented & $\begin{array}{l}\text { Assured and } \\
\text { could be } \\
\text { integrated }\end{array}$ & Not implemented \\
\hline
\end{tabular}

\section{Conclusions}

It has been determined that e-learning improvement is very important and can offer a perfect technology for individualized learning based on interactive learning objects as well as a group learning through online chat rooms. The model presents possibility of different LO integrations into platform or IS what would be created and designed not only for teachers but for the learners as well as they can be uniquely identified, the content can be specifically personalized, and learner progress can be monitored, supported and assessed. Both virtual and augmented reality could be integrated in the platform. Also, connection with social networks should be provided in the learning platform. The growing importance of the new technologies and its usage in creating new learning environments, implementation of new platforms, remain the object for further research for the authors of the present paper.

\section{References}

Cheng, K. H. (2018). Surveying Students' Conceptions of Learning Science by Augmented Reality and their Scientific Epistemic Beliefs. Eurasia Journal of Mathematics, Science and Technology Education, 14(4), 1147-1159.)

Diegmann, P., Schmidt-Kraepelin, M., Van den Eynden, S., Basten, D. (2015). Benefits of Augmented Reality in Educational Environments-A Systematic Literature Review. Wirtschaftsinformatik, 3(6), 1542-1556.

Endsley, M. R. (2016). Designing for situation awareness: An approach to user-centered design. CRC press.

Floyd, B., Santander, T., Weimer, W. (2017, May). Decoding the representation of code in the brain: An fMRI study of code review and expertise. In Proceedings of the 39th International Conference on Software Engineering (pp. 175-186). IEEE Press. 
Freeman, D., Bradley, J., Antley, A., Bourke, E., DeWeever, N., Evans, N., Slater, M. (2016). Virtual reality in the treatment of persecutory delusions: randomised controlled experimental study testing how to reduce delusional conviction. The British Journal of Psychiatry, bjp-bp.

Gallace, A., Spence, C. (2014). In touch with the future: The sense of touch from cognitive neuroscience to virtual reality. OUP Oxford.

Heverton, M., Teixeira, M. M., Aquino, C. D., Miranda, L., Freita, W. C., Coelho, A. (2016). Virtual Reality: Manipulating Multimedia Learning Objects. In International Conference on Web Research. Tehran, Irã. Anais do II ICWR.

Jamalahdin, Mostafa, Sayed Ahmad Hashemi, Pari Sosahabi, and Maryam Berahman. "The role of ICT in learning-teaching process." World Scientific News 72 (2017): 680-691.

Lee, N. Y., Lee, D. K., Song, H. S. (2015). Effect of virtual reality dance exercise on the balance, activities of daily living, and depressive disorder status of Parkinson's disease patients. Journal of physical therapy science, 27(1), 145-147.

Newman, F., Scurry, J. E. (2015). Higher education and the digital Rapids. International Higher Education, (26).

Pelargos, P. E., Nagasawa, D. T., Lagman, C., Tenn, S., Demos, J. V., Lee, S. J., Bari, A. (2017) Utilizing virtual and augmented reality for educational and clinical enhancements in neurosurgery. Journal of Clinical Neuroscience, 35, 1-4.

Radu, I. (2014). Augmented reality in education: a meta-review and cross-media analysis. Personal and Ubiquitous Computing, 18(6), 1533-1543.

Štuikys, V., Burbaitė, R., Bespalova, K., Blažauskas, T., Barisas, D. (2017). Stage-based generative learning object model for automated content adaptation. Baltic Journal of Modern Computing, 5(2), 183.

Weng, N. G., Bee, O. Y., Yew, L. H., Hsia, T. E. (2016). An augmented reality system for biology science education in Malaysia. International Journal of Innovative Computing, $6(2)$.

Wilson, C. J., Soranzo, A. (2015). The use of virtual reality in psychology: A case study in visual perception. Computational and mathematical methods in medicine, 2015

Yin, R. K. (2017). Case study research and applications: Design and methods. Sage publications.

Zhao, D., McCoy, A. P., Bulbul, T., Fiori, C., Nikkhoo, P. (2015). Building collaborative construction skills through BIM-integrated learning environment. International Journal of Construction Education and Research, 11(2), 97-120. 